\title{
PROTECTION OF BIOLOGICAL DIVERSITY
}

Y.V. Miroshnichenko, group EK-81

Life comes in an almost unending variety of shapes and sizes, and we all depend on this biodiversity for our food, health and security. This incredible natural wealth is a priceless resource. Loss of just one species could have untold effects on the world as we know it. So, the importance of safeguarding biodiversity is paramount.

The decade 2010 to 2020 has been designated the United Nations International Decade of Biodiversity. It's an opportunity for organizations across the world to come together and promote the importance of conserving the biodiversity on our planet.

There is a wide range of conservation organizations working to protect biodiversity. Different organizations have different objectives.

WWF, World Wildlife Fund, is the leading organization in wildlife conservation and endangered species. WWF's mission is to stop the degradation of the planet's natural environment and to build a future in which humans live in harmony with nature. Therefore, main activities of the organization consist of conserving the world's biological diversity and promoting the reduction of pollution. Now WWF is the largest conservation organization in the world with 5 million supporters, which working in more 100 countries and supporting over 1,300 environmental projects.

IUCN, The International Union for Conservation of Nature, is the oldest global environmental organization. Its mission is to influence, encourage and assist societies throughout the world to conserve the integrity and diversity of nature and to ensure that any use of natural resources is equitable and ecologically sustainable. IUCN influences on international environmental conventions, policies and laws in more than 1,200 government and non-governmental Member organizations. 11,000 experts of IUCN set global standards in their fields, for example, the definitive international standard for species extinction risk - the IUCN Red List of Threatened Species.

GEF, The Global Environment Facility, is the largest funder of projects to improve the global environment. An independent financial organization, the GEF provides grants to developing countries for projects related to biodiversity, climate change, international waters, land degradation and persistent organic pollutants and others. 